\title{
Comprehensive Experiment of the Process Control Instrument Technology Course
}

\author{
Tiecheng $\mathrm{Pu}^{1, \mathrm{a}}$ and Jing $\mathrm{Bai}^{1, \mathrm{~b}^{*}}$ \\ ${ }^{1}$ College of Electrical and Information Engineering, Beihua University, Jilin, 132021, China \\ aPutiecheng@163.com, bjilinbaijing@163.com
}

Keywords: Single tank; level control; Experimental system

\begin{abstract}
This project is based on the single tank water level control system as the core, to build a comprehensive engineering practice platform, through the integration of process control field of many kinds of knowledge, emphasize the training of students practical ability, improve the students' ability to solve practical engineering problems.
\end{abstract}

\section{Introduction}

Process control is one of the main subjects of measurement and control, process control system includes a transmitter, controller and actuator parts, including automatic detection technology, process control system, distributed control system, computer control system, process control instrument technology and other professional courses content. When students study professional courses, there is often not deep understanding of knowledge, comprehensive ability to use weak phenomenon. This project is based on the existing process control instrumentation skills training device as a platform for the development of engineering education through practice, let the students learn to design method of the process control system, and the integration of professional knowledge, to achieve the overall design of control system. The students with professional knowledge cultivate the ability of engineering design, practice and innovation ability.

\section{Significance of the Project Research}

The significance of this project is reflected in the following aspects:

(1) To provide a comprehensive engineering practice platform for students majoring in measurement and control.

In the past, most of the experimental equipment can only provide a unit, verification experiment for a course. In the process of experiment, students often passively operate according to the steps of the experiment instruction book, and can not give full play to their subjective initiative. The design of a comprehensive and practical platform for the research, considering the specialty of the outline requirements, can fully satisfy the teaching experiment, course design, graduation design, at the same time, students can design their own experimental scheme, comprehensive, creative process control system experimental design, debugging, analysis, students independent operation, independent ability to analyze and solve problems.[1]

(2) From the shallow and deep, comprehensive multi courses practice teaching, improve students' use of knowledge.

The experimental platform to carry out the "process control engineering", "automatic detection technology" and "process", "intelligent instrumentation control technology", "computer control system", "intelligent instrument design" and "virtual instrument" and an important professional course content, greatly improving the students' professional knowledge. At the same time, it is also helpful to carry out practical teaching activities such as experiment, practice and graduation design of measurement and control specialty.

(3) make full use of existing equipment, improve the utilization rate of existing equipment in practice teaching.

The newly introduced process control and measuring instrument skill training device in the measurement and control laboratory can provide the platform for testing, controlling and instrumentation in this course. 
Composed of the controlled object and the console on the device, by manual or computer control, the control object can be controlled into different characteristics, single loop control based on the liquid level can be simple temperature, pressure and flow, but also can be a series of cases of complex control system experiment.[2]

\section{Main Contents of the Project Research}

Device experimental platform for building the process of detection and process control process control instrumentation skill training using this project, to enable students to make full use of knowledge, master control system, the use of instruments and control system design and parameters setting of professional knowledge, and through the flexible design, build a system of events.

This project is to study the single loop level control system, analysis of working principle and measuring method of pressure type liquid level transmitter, understand the function of regulator and method of measuring object curve, analysis the first level characteristics. The electric control valve is used as the actuator, the structure of the valve and the calibration method of the control valve are analyzed, and the related characteristics are analyzed. Combined with the relevant knowledge to build a single loop level control system, to understand the liquid level characteristic curve measurement ideas and methods, master the object model parameters extraction method.

\section{The Experimental Principle of the Project}

This project is based on the process control measuring instrument skills training device as the platform, analyzes and studies the pressure level transmitter, regulator and electric actuator, and constitutes a single loop liquid level control system.

The training device is shown in figure 1. Composed of the controlled object and the console on the device, by manual or computer control, can be controlled into different characteristics of the controlled object, therefore, single loop control based on the liquid level can be simple temperature, pressure and flow, but also for a series of cases of complex control system experiment.

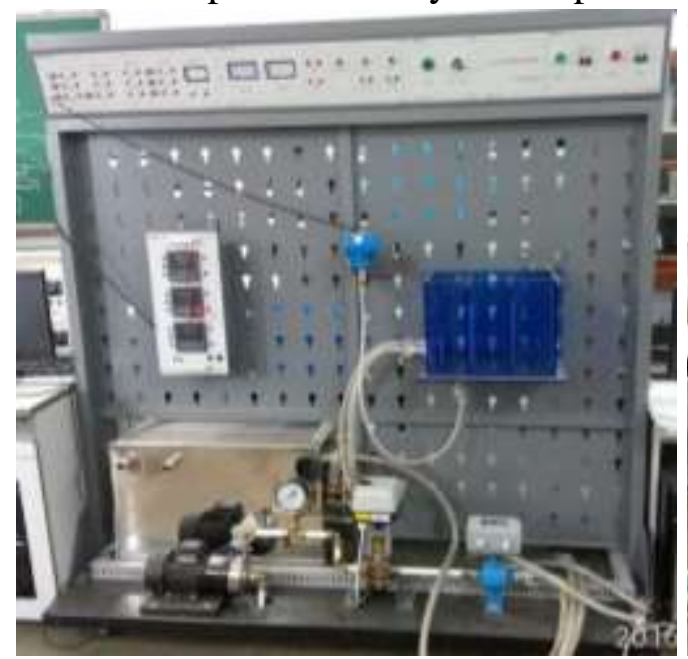

a) Positive

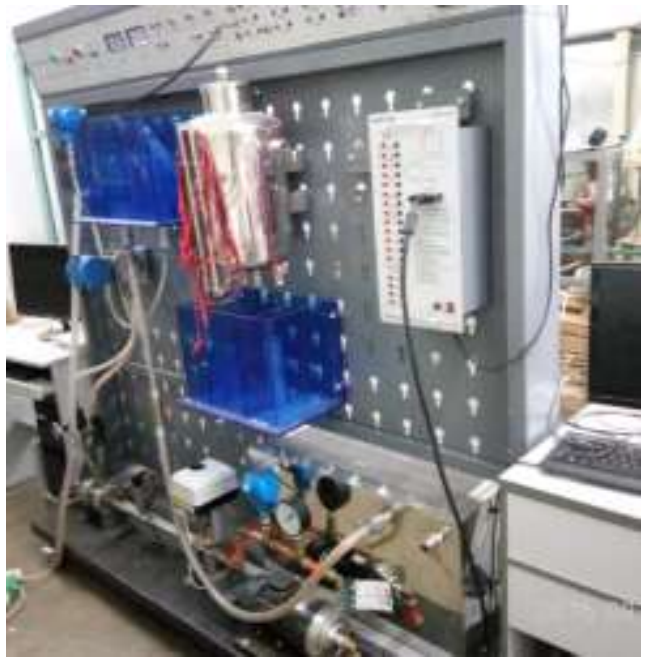

b) Back

Fig. 1 Skill training device for process control measuring instrument

The pressure transmitter can easily measure the liquid level, and can output standard pressure signal or current signal. It is the most widely used liquid level transmitter in industrial production. The structure diagram of the pressure level transmitter is shown in Fig. 2. For the open vessel with the upper end communicated with the atmosphere, the pressure gauge can be connected at the bottom, and the liquid level can be obtained from the relationship between the liquid level and the pressure from the pressure guide pipe. 


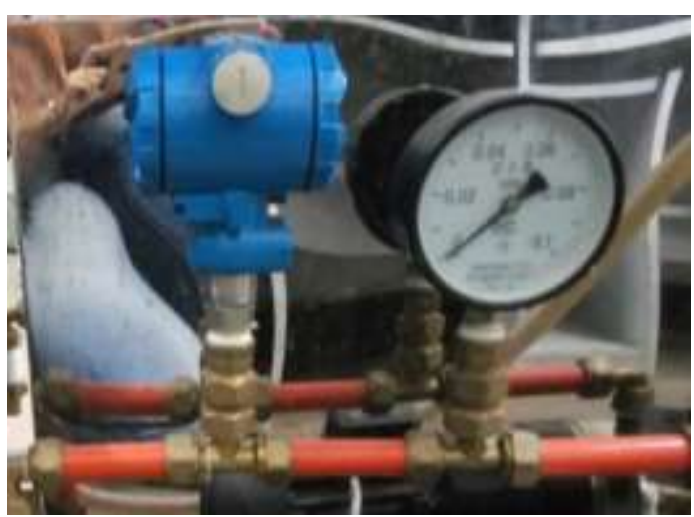

A) physical Diagram

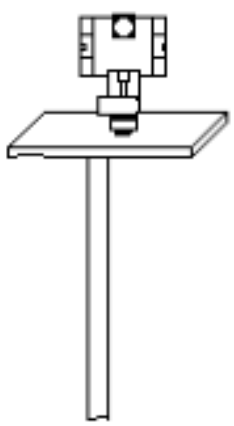

B) sketch

Fig. 2 pressure type liquid level transmitter

The main function of the regulator is that the liquid level receives the measurement signal PV sent by the transmitter, and compares it with the given signal SV to get the deviation epsilon. In the simple process control system, the tuning method of the parameters of controller can be used to determine the critical ratio method, the proportion of 8 , TI integral time and differential time TD, PID continuous operation of deviation epsilon, the output control signal $\mathrm{U}(\mathrm{K})$.

The electric control valve regulates the flow of the control circuit. The intelligent electric control valve, which has the advantages of high precision, advanced technology, small size, light weight, large driving force, strong function, control unit and electric actuator integration, high reliability, convenient operation, and can be matched with computer, the best form of regulation loop.

The students can design the single circuit liquid level control system by studying the transmitter, the regulator and the actuator. Jump to calculate the characteristic parameters of tau, T0, the mathematical model of K0 control system step response curve method with the PID parameter, the critical ratio method the whole order loop control system, familiar with the PID parameters on the control system of quality index, self tuning operation and automatic control of PID parameters using the regulator instrument or computer the. Master the parameter settings of the regulator and the use of manual and automatic functions.

The block diagram of the single closed loop control system controlled by the regulator is shown in figure 3 .

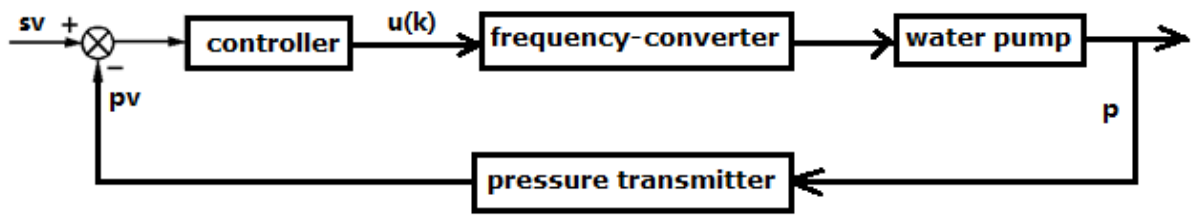

Fig. 3. block diagram of single closed loop control system for pressure control of regulator

With the computer as the controller, the output of the transmitter is sent to the computer through the A/D conversion module and compared with the set value. After analysis and calculation, the output signal is sent to the control valve through the D/A module. The block diagram of the single closed loop control system is shown in Fig. 4.

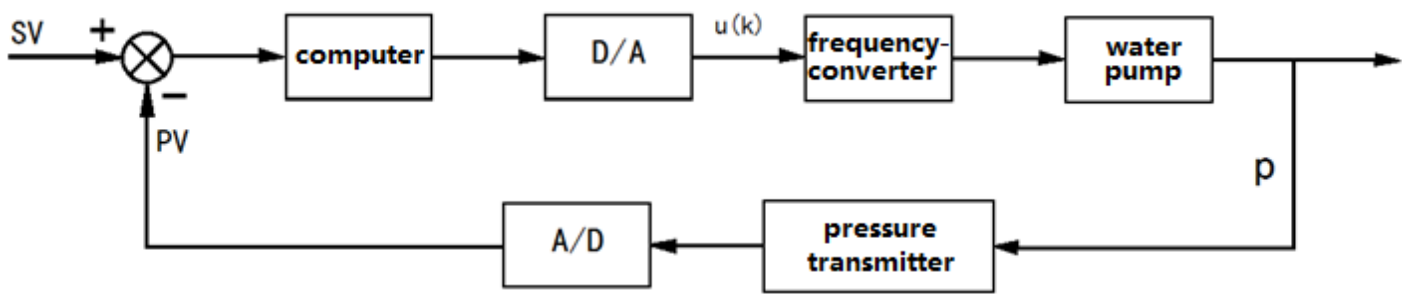

Fig. 4. block diagram of computer controlled pressure closed loop control system

Students through the transmitter, regulator and actuator learning, combined with the detection technology, process control, computer control and other related courses of knowledge, independent design, manual practice to complete the control of the liquid level. 


\section{Summary}

This project is based on the single tank water level control system as the core, to build a comprehensive platform of engineering practice, through the experiment, the object characteristics of single tank level pressure transmitter principle experiment, the electric control valve characteristic experiment, single tank water level control experiment, the single volume controlled object, transmitters, actuators and other knowledge fusion together, highlights the design and implementation of process control systems and cultivate the ability to maintain and improve students' ability to solve practical engineering problems in process control. At the same time, through the integration of the original experimental equipment, the experimental funds are saved, and the efficiency of the experimental equipment is improved.

\section{Acknowledgements}

This article is funded by the Education Department of Jilin Province under Grand No. 2015(135), and the major project of Beihua University "Research on talent training mode of automation specialty for new engineering need".

\section{References}

[1] T.C. Pu, J.C. Xu, H.X: Course education research, (2017)No.1,p.222.(In Chinese)

[2] J.B. T.C. Pu: China Education Innovation Herald.11(2011)No.4,p.73.(In Chinese) 